\title{
SELECTIVE MIGRATION ANALYSIS: A CASE STUDY OF THE MIGRATION OF POLISH HEALTHCARE STAFF $^{3}$
}

\begin{abstract}
This paper focuses on the issue of the migration of Polish healthcare staff. The goal of the paper is to analyze selective migration flows of Polish citizens using the example of healthcare staff and compare the results of the completed analysis with aggregated emigration flows. The completed analysis draws from data from the OECD database (2019) - Health Workforce Migration and International Migration Outlook from 2007 to 2017. There was created a unique data set, which made it possible to specify in greater detail the differences in preference when selecting a destination between common emigrants from Poland and healthcare staff. It was also possible to observe whether preferences differed among doctors and nurses and how their preferences differed over time. This paper uses statistical descriptions in order to record the development of emigration flows and correlation analyses for expressing changes in the preferences of Polish healthcare staff.
\end{abstract}

Keywords: migration, healthcare staff, nurses, doctors, shortage, preferences, analysis.

\section{INTRODUCTION}

The migration of healthcare staff is a highly significant topic dealt with on both the level of practice and scientific debates. However, the problem is that many professionals do not realize that healthcare staff is crucial for a high-quality and sustainable healthcare system and it is thus necessary to devote a larger amount of space to the given topic, as the situation with the shortage of high-quality healthcare staff is now alarming in many countries.

Aluttis et al. (2014) point out that healthcare is a quickly growing branch of the global economy. This fact is primarily influenced by globalization processes and the worldwide growth of demand for healthcare, the support of the healthcare technologies industry, and

\footnotetext{
${ }^{1}$ Ing. Pavlína Hejduková, Ph.D., University of West Bohemia, Faculty of Economics, Department of Finance and Accounting; e-mail: pahejdu@kfu.zcu.cz; Univerzitní 8, 30100 Pilsen. ORCID: 0000-0003-3387-1198.

2 Ing. Lucie Kureková, University of Economics, Prague, Faculty of Economics, Department of Economics; e-mail: xkurl06@vse.cz; W. Churchill Sq. 1938/4, 13067 Prague. ORCID: 0000-00027611-0463.

3 This paper was created within the project SGS-2017-004 'Finance and Sustainable Development from the Perspective of Theory and Practice' at the University of West Bohemia, Faculty of Economics.
} 
the opening of borders for the opportunity to work abroad on an EU level; all the aforementioned factors lead to cross-border migration of healthcare staff in the EU. An OECD study (2007) has shown that almost all EU member states depend increasingly on healthcare staff from abroad. Wismar et al. (2011) point to trends similar to this OECD study (2007), and state that countries such as Estonia, Slovakia and Poland rely very little on the use of foreign doctors (the demand ranges roughly from 0.02 to $0.7 \%$ of the overall workforce) and, on the contrary, countries like Switzerland, Slovenia, Ireland and the United Kingdom are among countries with a high dependence on foreign doctors (demand ranges roughly from $22.5 \%$ to as much as $36.8 \%$ of the overall labor force). As will be presented in the article using concrete data, Polish healthcare staff is typical for migration to countries with a high dependency on healthcare staff, which corresponds to the data given by Wismar et al. (2011).

As Afzal et al. (2012) state, despite the fact that the choice to migrate is a personal matter, the decision to migrate is influenced by many overall economic and social aspects. We can name "push and pull" factors for migration such as disparity in working conditions, financial rewards, the lack of promotion opportunities, unsuitable living conditions, the desire to gain new experiences, working on one's professional development, increasing household income, and so forth. There are many reasons why healthcare staff migrates and decides to work in a country different than its home country (for more see e.g. Mesquita \& Gordon, 2005; Bonner \& O'Brien, 2013; Oosthuizen, 2005).

However, the problem that is linked to migration of qualified staff - which is typical for healthcare - is the so-called brain drain, which has very serious impacts on the healthcare system of the home country, as qualified intellectuals (i.e. in this case doctors and nurses) leave their home country, causing a shortage of qualified healthcare staff in the given country (WHO, 2006; Gibson \& McKenzie, 2011).

This paper focuses on the issue of migration of Polish healthcare staff. The goal of the paper is to analyze the flows of the selective migration of Polish citizens using the example of healthcare staff and compare the results of the completed analysis with aggregated emigration flows.

This paper has been divided into several sections. In the first section of the paper, a literature review has been carried out. In the second, the goal of the paper is defined in more detail, the methodological approach is explained, and used data including a list of research limitations are described. The third section presents the results of the analysis and the completed statistical survey. The conclusion of the paper presents a summary of the primary research findings and additional potential directions of future research in the given area are outlined.

\section{LITERATURE REVIEW}

As was mentioned in the introductory section of this paper, migration of healthcare staff has been a phenomenon of the era of globalization for several years now (for more see e.g. Hejduková \& Kureková, 2016; Hejduková \& Kureková, 2017).

In light of the fact that this paper is focused on the issue of the migration of Polish healthcare staff, the studies mentioned below have been selected based on the specific focus of the paper.

One of the countries that has one of the most fundamental problems with healthcare staff, specifically in terms of the shortage of nurses, is the United Kingdom. As Abs.net 
claims (2019), the United Kingdom is no longer capable of maintaining present standards of healthcare, as around 40,000 more nurses are needed. At the same time, thanks to the referendum on Brexit, the number of nurse registrations from EU countries including Poland has significantly decreased since 2016; this fact will also be evident in the results of this paper. The United Kingdom is attempting to deal with the problem by hiring nurses from the Philippines; however, there are significant language barriers and the potential staff from these countries often cannot manage the complicated English-language tests.

Another country that faces serious problems due to a shortage of healthcare staff is Ireland. According to healthcare professionals' representatives, the Irish health system is "sleepwalking into another winter crisis" due to the HSE's inability to address the shortage of consultants, GPs and nurses in the public service. Peadar Gilligan, president of The Irish Nurses and Midwives Organisation said that "the recruitment and retention problem in Ireland is now at crisis point" (Irish Examiner, 2018).

As can be observed from available data, a more fundamental problem is beginning to appear among nurses, primarily in the context of general nursing and the ageing of the population. If we summarize the data published by Simoens at al. (2005), the majority of OECD countries seem to be suffering from nurse shortages. Some countries have published estimates of how many headcounts or full-time equivalent nurses per year over the next decade would be needed to match demand for and supply of nurses. Australia reports a shortage of around 6000 registered nurses (around 3\% of practicing registered nurses) (Access Economics, 2004, O'Hagan, 2002). Conservative estimates of Canada's shortage of registered nurses put the number in the range of 16000 (Canadian Nursing Advisory Committee, 2002) or $6.9 \%$ of the present workforce. The Netherlands has reported a shortage of 7000 nurses (1\% of the practicing registered nurse workforce). The shortage of nurses in Norway has been estimated at 3300 full-time equivalents or about $5.4 \%$ of practicing nurses (Askildsen et al., 2003). There are 3000 (4.6\%) fewer generalist nurses in Switzerland than required (Irwin, 2001). The United States government reported a shortage of 110700 registered nurses (5\% of the practicing registered nurse workforce) in 2000 (National Centre for Health Workforce Analysis, 2002).

Scheffler \& Arnold (2019) develop in their research study a projection model for the demand of doctors and nurses by OECD countries in the year 2030. Their model is based on a country's demand for health services, which includes the following factors: per capita income, out-of-pocket health expenditures and the ageing of its population. The supply of doctors and nurses is projected using country-specific autoregressive integrated moving average models. Results of this research study show that it is possible to expect a shortage of nearly 400,000 doctors across 32 OECD countries and a shortage of nearly 2.5 million nurses across 23 OECD countries in 2030.

According Kaminska \& Kahancova (2011), the healthcare sector in the EU is strongly affected by migration in Slovakia, Poland and Hungary. This fact is one of the reasons for the selection of this paper's focus on migration of Polish healthcare staff.

Articles focused on Polish healthcare staff have been published by e.g. Szapakowski et al. (2017), in which the authors have analyzed the migrations of nurses and doctors from Poland: data for the years 2014-2020 based on the sample of the capital city of Warsaw. Their studies have pointed out the differences in motivation and the barriers and reasons for the migration of Polish doctors and nurses. Their statistical analysis shows that the decision to migrate among the doctors in the study was influenced by their previous work abroad and participation in recruitment company meetings. In the case of the nurses in the study, 
the situation was different; recruitment companies and subsequently previous practice abroad played a significant role.

Haczyński et al. (2017) decided to analyze changes in the size of the population of nurses in Poland from 2004 to 2014 with regard to changes in their employment and the phenomenon of ageing. The reason for the selection of this topic was primarily the fact that nurses are the largest professional group in the field of healthcare. The analysis draws on data published by the Central Register of Nurses and Midwives of the Central Statistical Office (GUS) and the OECD. The authors point out that the profession of nurse has no substitute generation in Poland and claim that there is a fundamental shortage of professionally active nurses in the country. At the same time, the authors cite the problem of incomplete information from the Register or Nurses and thus also to limitations of the study.

Wolk (2016) claims that, in regard to limiting the departure of healthcare staff, reforms of the healthcare system in Poland have been highly ineffective and have not supported return migration. The author emphasizes the fact that reforms of the healthcare system have to be implemented in the whole healthcare sector and must focus on drastic financial restructuring.

Hongyan et al. (2014) also point to the dramatic shortage of nurses on a worldwide scale. In their paper, they claim that migration has a significant impact on the individual and national level and summarize the factors that contribute to the migration of nurses from the perspective of the source and receiving country. A specific element of the paper is also the discussion on the ethical questions surrounding the migration of nurses. They introduce the question of whether nurses should be accepted abroad, especially if they are from developing countries or countries already experiencing a nursing shortage (Sparacio, 2005; Omeri, 2006). They also discuss the question of how source countries have invested in the education of nurses, who later leave to other countries (for more see e.g. McElmurry, 2006).

As is clear from the aforementioned list of literature, the migration of healthcare staff is a heated topic not only on the level of doctors, but also of nurses (which is perhaps even more common). At the same time, we can assume an increase in the shortage of healthcare staff not only for reasons of migration from one country to another, but also due to the heightened need to increase the numbers of staff in the context of the ageing of the population.

\section{METHODOLOGY AND DATA}

The goal of the paper is to analyze the flows of the selective migration of Polish citizens using the example of healthcare staff and compare the results of the completed analysis with aggregated emigration flows. The analyzed period is from 2007 to 2017 (the last available data is from 2017). The data was taken from the OECD database (2019) - Health Workforce Migration and International Migration Outlook. The database keeps data on the migration of citizens from Poland and Polish doctors and nurses. Data are collected for the member states of the OECD. Unfortunately, the timelines are not always complete and very often information on OECD member states is missing; for example, the Czech Republic does not provide information on the number of nurses from abroad. Such discrepancies can naturally have an impact on the results of our analysis; nonetheless, we believe that the despite this fact our results will bring new findings and that this paper will point to the urgency of the necessity for better statistical reporting in the field of Health Workforce Migration in OECD countries. 
In order to carry out the analysis of selective migration from Poland, we observed OECD member states in which an influx of Polish citizens with the profession of doctor or nurse was recorded. This created a unique data set, which made it possible to observe the selection of destinations made by Polish healthcare staff from 2007 to 2017. Thanks to this data set, we were able to look in more detail at the differences in preferences in the selection of destinations among common emigrants from Poland and healthcare staff. It was also possible to observe how preferences differ among doctors and nurses and how their preferences changed over time.

The analysis has been divided into several steps. The first step identifies countries to which Polish citizens most often emigrated. In terms of its statistical research on international migration, the OECD publishes basic summaries on each member state. A part of the OECD - International Migration Outlook summary is a list of 10 states (the so-called Top 10) to which Polish citizens most often migrated. The data contains information for 2017 and for the years 2007-2016. The list of the Top 10 states according to the OECD (2019) is shown in Fig. 1.

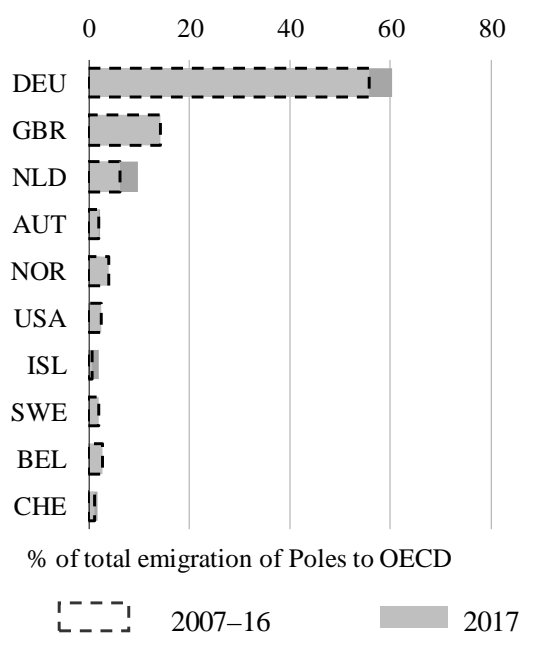

Figure 1. Emigration of Poles to OECD countries - TOP 10 countries

Source: OECD (2019) - International Migration Outlook, authors` own depiction

The second step identified countries to which Polish healthcare staff most often emigrated. Data from the OECD - Health Workforce Migration was used, in which 10 states (or the Top 10) to which Polish healthcare staff most commonly emigrated were identified. The data contain information divided into doctors and nurses. In light of the fact that annual flows can be influenced by the volume of current Polish healthcare staff in the host country, two statistical indicators for recording preferences were observed: Foreign-trained staff annual flows and stock (doctors and nurses). Statistical indicators were first expressed cumulatively for the years 2007-2016; according to this cumulative sum, states were ordered from the largest volume of migration flows or the stock of foreign trained doctors and nurses. Subsequently the proportion of individual host states in overall emigration in 2017 
and for the 10-year reference period from 2017 to 2016 was calculated. The summary of the Top 10 states is shown in Fig. 2.

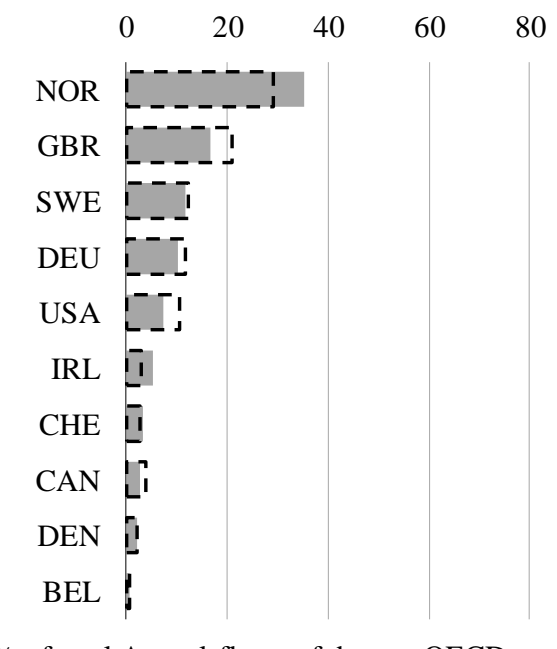

$\%$ of total Annual flows of docs to OECD

$20-40-60-80$

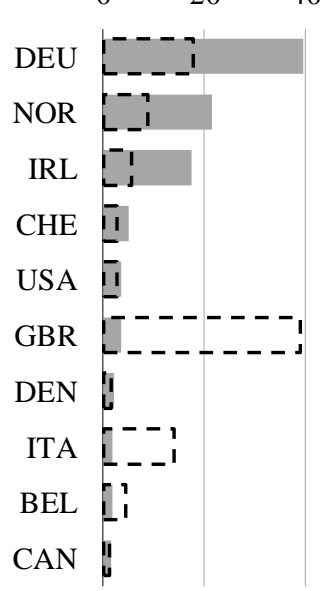

$\%$ of total Annual flows of nurse to OECD

$$
\text { I }
$$

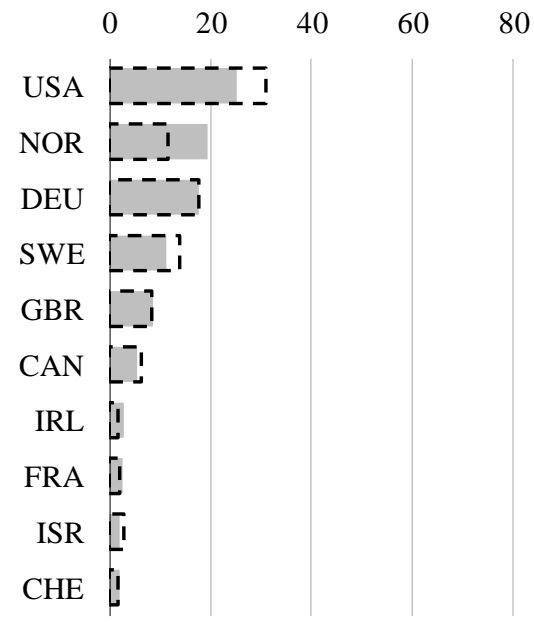

$\%$ of total Stock of docs in OECD
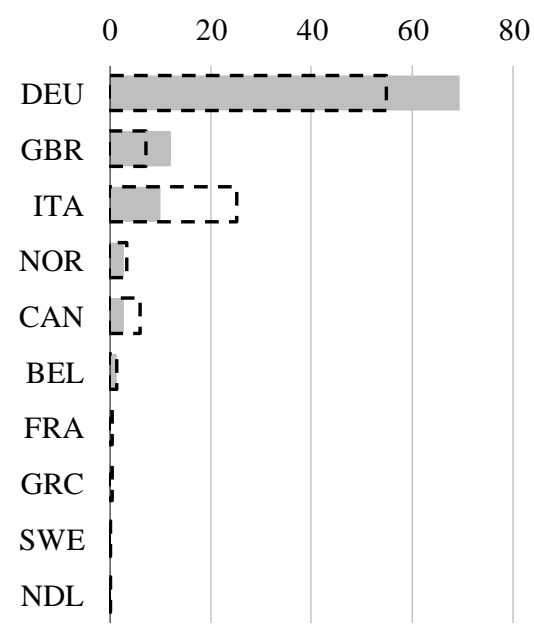

$\%$ of total Stock of nurse in OECD

2017

Figure 2. Emigration of Polish medical staff to OECD countries - TOP 10 countries

Source: OECD (2019) - Health Workforce Migration, authors“ own depiction; *data for 2017 were not available; with the help of OLS, values for 2017 were estimated, **only the reference period is listed, as data for 2016 and 2017 were not available.

The third step identified the differences in the preferences of migrating citizens and healthcare staff. Based on the Top 10 analysis of states presented in Figures 1 and 2, 
a comparison of the order of states can be carried out. Thus it is possible to find out which host states were most preferred by citizens of Poland and by healthcare staff. Furthermore, it is possible to compare more closely the volume of annual flows and the overall number of doctors and nurses. In conclusion, the closeness of the dependency of preferences between the reference period of 2007-2016 and the year 2017 was measured in order to find out whether a change took place in 2017 in the selection of the host state compared to the average development in the past 10 years. Dependence was measured via the Pearson correlation coefficient (pwcorr). If the pwcorr value takes on values close to 1 , it is possible to assume that no change in preferences took place compared to the referential period between 2007 and 2016. On the contrary, if pwcorr values are close to zero or even negative, it can be assumed that a change in preferences took place.

For a more detailed picture of the acquired data set on the emigration of healthcare staff from Poland, basic descriptive statistics such as mean, standard deviation, minimum and maximum were calculated. In Table 1, these statistics for the TOP 10 states are listed, i.e. host states are listed to which migration flows most often travel and in which there is the largest proportion of Polish healthcare staff abroad. According to the "time period" column, we can see that complete timelines are unfortunately not always available. Incomplete data most often appear among statistics following the migration of nurses.

\section{RESULTS}

If we compare the mean annual values of the Stock of Polish doctors and nurses in total (i.e. the sum for all OECD states), it is evident that there are more nurses $(12,522)$ than doctors $(8,334)$ abroad in the studied period. The value for nurses may be undervalued due to incomplete statistics; there are likely even more of them abroad than the calculated value from available statistics. If we look at the overall dynamics of emigration flows of Polish healthcare staff and thus indicators of annual flows of Polish doctors and Nurses, the annual flows were higher for doctors (845) than nurses (665).

Fig. 1 shows that during the observed period, Polish citizens primarily preferred Germany as the host country. Almost $60 \%$ of emigration flows from Poland went to Germany; then at some distance followed Great Britain and Holland. In addition, interest in Germany and Holland increased in 2017 compared to the reference period. It is possible to expect that, thanks to the situation stemming from Brexit, Polish citizens will prefer the German labor market.

The preferences of doctors in selecting a target country is significantly different from aggregated emigration flows from Poland. Figure 2 clearly shows that in the studied period doctors primarily preferred Norway, then Sweden and Great Britain. A historically large proportion of doctors are in the USA, Norway and Germany. We can thus claim that doctors do not copy the scheme of decision making that is typical for aggregated emigration flows in the selection of a host country (Fig. 1).

On the contrary, the preferences of nurses in the selection of a target country copy aggregated emigration flows; nurses preferred the German labor market. In 2017, growth of emigration to German, Norway and Ireland is evident. Furthermore, it is possible to observe a weakening interest in the Italian labor market. The heightened interest in Ireland in 2017 may be explained to a certain degree by the situation in Great Britain, which culminated in the vote to exit the EU (i.e. Brexit). 


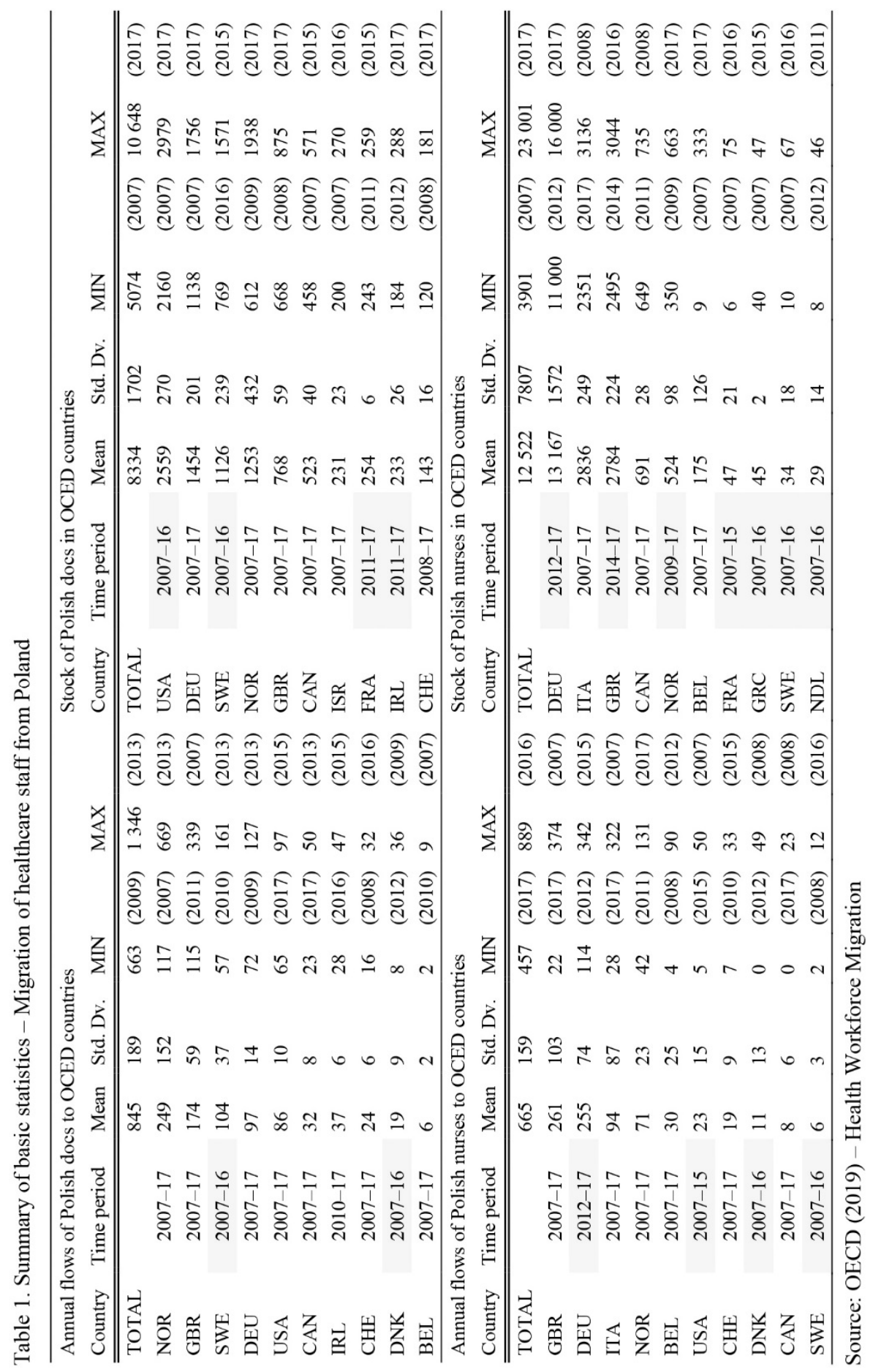


The dependence of decision making between the reference period and 2017 was measured using the Pearson correlation coefficient (pwcorr). Results in Table 2 show that the indicator of overall emigration (EMIGRATION) and almost all indicators of selective migration with the exception of NURSE ANNUAL FLOW are pwcorr values close to 1. Pwcorr was very low (pwcorr=0.28) for the Nurse annual flow indicator. Thus in the case of aggregated emigration flows, results show that in 2017 a significant change took place in the preferences - this conclusion is identical to migration flows of doctors. On the contrary, in the case of migration flows of nurses the low pwcorr (NURSE ANNUAL FLOW) implies that in 2017 a change occurred in the preferences in the selection of host countries compared to the reference period. This change was caused by a lower degree of interest in Great Britain in 2017 and heightened preferences for the labor market in Germany and Norway.

Table 2. Results of the closeness of dependence between the reference period 2007-2016 and 2017

\begin{tabular}{lccccc}
\hline & EMIGRATION & $\begin{array}{c}\text { DOCTOR } \\
\text { ANNUAL } \\
\text { FLOW }\end{array}$ & $\begin{array}{c}\text { DOCTOR } \\
\text { STOCK }\end{array}$ & $\begin{array}{c}\text { NURSE } \\
\text { ANNUAL } \\
\text { FLOW }\end{array}$ & $\begin{array}{c}\text { NURSE } \\
\text { STOCK }\end{array}$ \\
\hline \hline pwcorr & 0.99 & 0.95 & 0.96 & 0.28 & 0.95 \\
t-test & 23.83 & 8.84 & 9.80 & 0.81 & 8.58 \\
p-value & 0.000 & 0.000 & 0.000 & 0.624 & 0.000 \\
\hline
\end{tabular}

Source: OECD (2019) - International Migration Outlook and Health Workforce Migration, authors" own depiction

\section{CONCLUSION}

This paper has dealt with the issue of the migration of Polish healthcare staff. The goal of the paper was to analyze the flows of selective migration of Polish citizens using the example of healthcare staff and to compare results of the completed analysis with aggregated emigration flows.

As was discovered from the completed research, not only Poland but other developed countries face problems in their healthcare systems, and issues with securing high-quality staff are at the forefront of all problems in the field of healthcare.

OECD countries of course deal with the shortage of staff by acquiring foreign employees with healthcare education, which is a significant characteristic of globalization. This fact is of course accompanied by various pluses and minuses and the phenomenon of migration flows of healthcare staff should be viewed from both the perspective of the country from which this staff flows and the perspective of the country to which this staff has come to work.

Based on studied scientific sources, we can claim that the migration of nurses is becoming a more significant problem in terms of the migration of healthcare staff, although the migration of doctors is also crucial in observing healthcare systems. Different motivation to migrate and different preferred countries have been found among nurses and doctors.

In the completed analysis, Polish citizens primarily preferred Germany as the host country during the studied period. Almost $60 \%$ of emigration flows from Poland went to Germany; then at some distance followed Great Britain and Holland. Nurses in the selection of a target country copy copied aggregated migration flows and doctors on the contrary had 
different preferences, primarily preferring Norway, then Sweden and Great Britain. A large proportion of Polish doctors have historically worked in the USA, Norway and Germany.

Furthermore, the results of the analysis have shown that a change of preferences did not take place in 2017 in terms of aggregated migration flows and the selective migration of doctors. In terms of nurse migration flows, a change in the preferences of host country selection took place in comparison to the reference period. This change was caused by lower interest in Great Britain, and also in Italy in 2017, and heightened preferences in the labor market in Germany, Norway and Ireland. The heightened interest in Ireland in 2017 may to a certain degree be caused by the situation in Great Britain, which culminated in the vote to exit the EU (i.e. Brexit).

This paper also mentions the issue of incomplete data in the field of selective migration of healthcare staff; specifically, a lack of incomplete data most often appears in statistics on the migration of nurses. The paper thus points to the urgency of the necessity for better statistical reporting in the field of Health Workforce Migration in OECD countries, as these discrepancies can naturally have an influence on the results of further analyses and the ability to replicate the research in general.

\section{REFERENCES}

Abc.net. News. Brexit will worsen UK's nursing shortage, and language tests are thwarting the solution Access on the Internet: https://www.abc.net.au/news/2019-04-09/brexit-will-worsenuk-nursing-shortage-and-solution-is-stymied/10982816

Afzal, S., Masroor, I. \& Shafqat, G. (2012). Migration of health workers: a challenge for health care system. "Journal of the College of Physicians and Surgeons Pakistan", 22(9). Access on the Internet: https://ecommons.aku.edu/pakistan_fhs_mc_radiol/218

Aluttis, Ch., Bishaw, T. \& Martina W.F. (2014). The workforce for health in a globalized context - global shortages and international migration. "Global Health Action", 7:1. DOI: 10.3402/gha.v7.23611.

Bonner, A. \& O'Brien, L. (2013). Why do nurses migrate? A review of recent literature. "J Nurs Manag”, 21: 511_20.

de Mesquita, J.B. \& Gordon, M. (2005). The international migration of health workers: a human rights analysis. Medact. Access on the Internet: http://www.equinetafrica.org/bibl/docs/ BUEhres.pdf

Gibson, J. \& McKenzie, D. (2011). Eight questions about brain drain. "The Journal of Economic Perspectives".

Haczynski, J., Skrzypczak, Z. \& Winter, M. (2017). Nurses in Poland - Immediate Action Needed. "Ekonomia i Zarzadzanie”, 9(3). DOI: 10.1515/emj-2017-0019.

Hejduková, P. \& Kureková, L. (2016). The globalized world and migrants: impacts on healthcare markets. In Globalization and Its Socio-Economic Consequences. Žilina: ZU - UNIVERSITY OF ZILINA, 2016.

Hejduková, P. \& Kureková, L. (2017). Migration of nurses: serious global health problem [in:] Globalization and Its Socio-Economic Consequences. Žilina: ZU - UNIVERSITY OF ZILINA. 
Irish Examiner (2018). Medics' unions warn of staff shortages. Access on the Internet: https://www.irishexaminer.com/breakingnews/ireland/medics-unions-warn-of-staff-shortages859169.html, Wednesday, August 01, 2018-06:00 AM By Joe Leogue.

Kaminska, M.E., \& Kahancova, M. (2011). Emigration and Labour Shortages: An Opportunity for Trade Unions in the New Member States? "European Journal of Industrial Relations”, 17(2). DOI: https://doi-org.zdroje.vse.cz/http://ejd.sagepub.com/archive/.

McElmurry, B.J. et al. (2006). Ethical concerns in nurse migration. "J Prof Nurs", 22(4).

OECD (2007). Immigrant health workers in OECD countries in the broader context of highly skilled migration. Access on the Internet: http://www.who.int/hrh/migration/2007_annual_report_international_migration.pdf.

OECD (2019). Health Workforce Migration. Access on the Internet: http://stats.oecd.org/\#. OECD (2019). International Migration Outlook 2019. Paris: OECD Publishing. DOI: $10.1787 / \mathrm{c} 3 \mathrm{e} 35 \mathrm{eec}-\mathrm{en}$.

Omeri, A. (2006). Workplace practices with mental health implications impacting on recruitment and retention of overseas nurses in the context of nursing shortages. "Contemp Nurse", 21(1).

Oosthuizen, M.J. (2005). An analysis of the factors contributing to the emigration of South Africa nurses. PhD Dissertation, University of South Africa, Pretoria, 177.

Scheffler, R. \& Arnold, D. (2019). Projecting shortages and surpluses of doctors and nurses in the OECD: What looms ahead. "Health Economics, Policy and Law", 14(2). DOI: 10.1017/S174413311700055X.

Simoens, S., Villeneuve, M. \& Hurst, J. (2005). Tackling Nurse Shortages in OECD Countries. "OECD Health Working Papers" No. 19. Access on the Internet: https://www.oecd.org/ health/health-systems/34571365.pdf.

Sparacio, D.C. (2005). Winged migration: international nurse recruitment friend or foe to the nursing crisis? "Journal of Nursing Law”, 10(2).

Szpakowski, R. (2019). Migrations of nurses and doctors from Poland: data for the years 2014-2020 based on the sample of the capital city of Warsaw. "Arch Med Sci”, 15(3). DOI: 10.5114/aoms.2017.69394.

WHO (2006). The world health report 2006 _working together for health. Geneva, Switzerland: World Health Organization.

Wismar, M et al. (2011). Health professional mobility and health systems in Europe: an introduction [In:] Wismar, M., Maier, C.B., Glinos, I.A., Dussault G., Figueras J., eds., Health professional mobility and health systems: evidence from 17 European countries. "Brussels: European Observatory on Health Systems and Policies".

DOI: $10.7862 /$ rz.2019.mmr.27

The text was submitted to the editorial office: December 2019.

The text was accepted for publication: January 2020. 
